\title{
ION IMPLANTATION FOR CORROSION INHIBITION OF ALUMINUM ALLOYS IN SALINE MEDIA
}

J. M. Williams, Oak Ridge National Laboratory,* Oak Ridge, TN

A.Gonzales, AVSCOM-DERSO, Corpus Christi, TX

J. Quintana, Corpus Christi Army Depot, Corpus Christi, TX

I-S Lee and R. A. Buchanan, The University of Tennessee, Knoxville, TN

F. C. Burns, R. J. Culbertson, and M. Levy, U. S. Army Materials Technology Laboratory, Watertown, MA

J. R. Treglio, ISM Technologies, Inc., San Diego, CA

\section{Abstract}

The effects of ion implantation treatments on corrosion of 2014 and 1100 aluminum in saline media were investigated. Implanted ions were $\mathrm{N}, \mathrm{Si}, \mathrm{Ti}$ and $\mathrm{Cr}$. Techniques included salt spray testing, electrochemical studies, Rutherford backscattering spectrometry, and profilometry. It was conciuded that ion implantation of $\mathrm{Cr}$ is of potential practical benefit for corrosion inhibition of $2014 \mathrm{Al}$ in salt environments.

\section{Introduction}

Aluminum and its alloys are vulnerable to corrosion by pit initiation when exposed to saline environments such as sea water, salt spray and marine atmospheres. In particular, the wrought commercial alloy, $2014 \mathrm{Al}$, is more susceptible to corrosion in salt environments than some other aluminum alloys. Because of superior mechanical properties, however, this composition finds use in aircraft construction. Better protection of $2014 \mathrm{Al}$ surfaces against pitting corrosion would result in more highly optimized components, and thus could contribute to better overall performance of aircraft systems.

* Kesearch sponsored by the Division of Materials Sciences, U.S. Department of Energy under contract DE-AC05-84OR21400 with Martin Marietta Energy Systems, Inc. 
The results of the present paper form part of a larger and continuing study on use of ion implantation treatments for corrosion inhibition of aluminum in saline environments. Results are presented for the ion species, nitrogen, chromium, titanium and silicon, as implanted into $2014 \mathrm{Al}$. The engineering test consisted of salt spray exposure. Other techniques included electrochemical and Rutherford backscattering (RBS) analyses. For comparison with the results from $2014 \mathrm{Al}$, parallel studies have also been done on $1100 \mathrm{Al}$, a nominally pure commercial aluminum.

It will be concluded that ion implantation of chromium is quite effective as corrosion protection for $2014 \mathrm{Al}$.

\section{Experimental Procedures}

\subsection{Processing, testing, and analyses}

Ion implantations were performed by use of a Varian/Extrion 200-1000 implanter, a well-known design which provides for magnetic analysis of beam. The sample coupons were secured to a cooled Ni-block type of target holder for implantation. Temperatures of the block ranged from -10 to $40^{\circ} \mathrm{C}$ during the implantations. From previous tests it can be concluded that, for a ductile material such as $\mathrm{Al}$, secured to the block, the sample temperature is no more than $5^{\circ} \mathrm{C}$ higher than the block temperature. Vacua during implantations ranged from $8 \times 10^{-7}$ torr down to $2 \times 10^{-7}$ torr. Fluencies and energies will be stated in the results, except for certain of the nitrogen implantations. Some nitrogen treatments were intended to produce more-or-less flat concentration profilcs of specified concentration to depths of about 0.25 microns. The treatment consisted of three 
implantations at combinations of fluences and energies designed by calculation [1] to achieve the desired concentration. For example, for 20 at. $\% \mathrm{~N}$ the parameters were $5.3 \times 10^{16} / \mathrm{cm}^{2}$ at $17.5 \mathrm{keV}, 6.0 \times 10^{16 / \mathrm{cm}^{2}}$ at $32 \mathrm{keV}$ and $2.0 \times 10^{17} / \mathrm{cm}^{2}$ for $65 \mathrm{keV}$. Proportional adjustments were made for the 10 at. $\%$ and 30 at.\% profiles. Dosimetry was by current integration during implantation. For $\mathrm{Cr}$ and $\mathrm{Ti}$ implantations, dosimetry was confirmed by use of Rutherford backscattering spectrometry (RBS).

Salt spray (fog) testing was conducted according to the ASTM Standard Method described in ASTM Designation B 117-73 [2]. In concept, the test consists of placing the samples in a large chamber into which salt fog is continually introduced by atomization. In compliance with the specification, the environment temperature was $35+-1^{\circ} \mathrm{C}$, the $\mathrm{pH}$ was between 6.5 and 7.2 , the $\mathrm{NaCl}$ concentration was $5+-0.5 \mathrm{wt} . \%$, and the fog density was such as to produce 1.8 milliliters of condensate per hour (average) per $80 \mathrm{~cm}^{2}$ at area.. Exposure time was $168 \mathrm{~h}$.

For electrochemical experiments, samples were immersed in 1 wt. $\% \mathrm{NaCl}$ deaerated solution. Studies consisted of potentiodynamic cyclic anodic polarization experiments.

Rutherford backscattering spectrometry (RBS) [3] analyses made use of He ions at 2.0 MeV incident energy. The scattering angle was $160^{\circ}$ for all analyses.

Profilometry was by use of of a Dektak IIA profilometer equipped with a submicron stylus.

\subsection{Starting materials}

The composition of $2014 \mathrm{Al}$ is nominally $4.4 \mathrm{wt} . \% \mathrm{Cu}, 0.8 \mathrm{wt} . \% \mathrm{Si}, 0.8 \mathrm{wt} . \%$ $\mathrm{Mn}$, and $0.5 \mathrm{wt} . \% \mathrm{Mg}$, the balance being $\mathrm{Al}$. The 1100 alloy is $99 \mathrm{wt} . \% \mathrm{Al}$ minimum, 
with the princinal alloying constituent being $\mathrm{Cu}$ at the $0.1 \mathrm{wt} . \%$ level. The 2014 was in the hard form (T6).

Starting surfaces were prepared by two types of polishing processes. The first (named "A") was a metallographic technique which made use of a colloidal silica polishing compound. This compound has a $\mathrm{pH}$ of about 9 . This treatment produced a very bright and mirror-like surface on $1100 \mathrm{Al}$. On $2014 \mathrm{Al}$ the surface was also very bright but was considerably more wavy in texture than the surface on the 1100 . This result is presumably connected with the presence of Cu precipitates in the 2014. The "mechanical" polish consisted of first grinding and polishing the surface to a finish of 0.1 micron RMS. Then the samples were further polished by use of 2-6 micron diamond paste. Although smooth, these surfaces were not as lustrous as those produced by the "A" polish. Starting surfaces for $1100 \mathrm{Al}$ were produced only by the "A" polish. Either polish was used for respective samples of 2014.

Rutherford backscattering spectra for typical starting surfaces are shown in Fig. 1. The most important point is that the "A" polish produces some enhancement of $\mathrm{Cu}$ concentration at the surface of $2014 \mathrm{Al}$, apparently due to preferential removal of $\mathrm{Al}$ by the somewhat caustic polishing compound. This can be seen by comparing curves 1 and 2 in Fig. 1. It later turned out that samples with the " $A$ " polish performed worse in pitting corrosion than samples with the mechanical polish. There was even some enhancement of $\mathrm{Cu}$ concentration at the surface of the $1100 \mathrm{Al}$ (curve 4). Another spectrum for mechanically polished $2014 \mathrm{Al}$ (curve 3) is also shown in Fig. 1. Comparison of curves 2 and 3 demonstrates that there was variability in the amount of $\mathrm{O}$ incorporated into the nearsurfaces among mechanically polished samples. The amount of $O$ in the near-surface for curve 2 (Mechanical 1) for example was $1 \times 10^{17} / \mathrm{cm}^{2}$, whereas $O$ was not detected for Mechanical 2. It is suspected that heating during the grinding process is the factor that determines the amount of $O$ in the surface of as-prepared samples. 


\section{Results}

Figure 2 is a photograph of coupons of 2014 alloy for the respective conditions indicated. The salient impression presented by the photograph can be taken as a rather accurate representation of the relative merits of these particular implantation treatments. The implanted area of $\mathrm{Cr}$-implanted sample has no visible pits, but is in fact somewhat less bright than the new sample, due to addition of some $O$ (see below). The Ti-implanted sample may be slightly under represented in merit by this particular lighting, but there are a few pits, particularly near the periphery of the implanted area. The low dose Si implant is of no benefit, and the high dose is of some slight benefit. Nitrogen implanted samples of $2014 \mathrm{Al}(10$ at. \% N, 20 at.\% $\mathrm{N}$ and 30 at.\% N) are not shown. The $\mathrm{N}$-implanted samples of $2014 \mathrm{Al}$ were all indistinguishable from unimplanted ones after salt spray testing. Therefore, $\mathrm{N}$-implantation of $2014 \mathrm{Al}$ was considered to provide no benefit against corrosion in this severe salt spray test.

Oxide coatings from unimplanted areas are not reflective, but in some cases exhibit a white coloration. There are some small reflective areas in between the large patches of oxide.

Figure 3 is a profilometry trace for which the stylus has travelled from the implanted to the unimplanted area for the Cr-implanted sample of Fig. 2. The elevation of the original surface is well defined by the Cr-implanted area. On the unimplanted area large patches of oxide, which have apparently grown from pit nuclei, are 30 microns thick. Between these oxide areas are other areas which have not been severely oxidized, and which remain somewhat reflective. This oxide texture is typical of that for unimplanted samples for both 2014 and $1100 \mathrm{Al}$, except that for 1100, there are fewer pit 
nuclei and oxide patches. The reflective areas in between the oxidized areas are somewhat more prominent for 1100 .

Figure 4 shows RBS histograms for the Cr-implanted sample of Fig. 1 and for an as-implanted sample. For the implanted and tested sample it is evident that some $O$ has been added by the 168-h salt spray exposure. The concentration of oxygen corresponding to the peak in the implanted and tested sample is $3.5 \times 10^{17} / \mathrm{cm}^{2}$. If all of this oxygen were added by the test, the corresponding weight gain would be only $9.3 \times 10^{-6} \mathrm{gm} / \mathrm{cm}^{2}$. The amount of $\mathrm{O}$ on the surface before implantation or after implantation for this particular sample is not known, however. Thus, the value quoted for added oxygen can be considered to be the maximum.

The $\mathrm{Cr}$ and $\mathrm{Al}$ edges remain at the same energies as before the test. Thus, it can be concluded that no unknown substances of appreciable thickness are covering the surface. Some implanted $\mathrm{Cr}$ is essentially all the way out to the surface for both cases. Owing to addition of oxygen within the implanted layer, the $\mathrm{Cr}$ peak just back of the surface has been somewhat broadened. The oxygen contributes to inelastic loss of the He ions, and thus spreads the Cr backscattering events out over a wider energy range than for the untested case. Within 3\%, the amount of $\mathrm{Cr}$ in the two peaks is the same. Further quarıtification is presented below.

The RBS histogram for the Ti-implanted 2014 Al sample of Fig. 2 is qualitatively similar to that for Cr. Aboul twice as much oxygen was added as for the Cr-implanted, and the Ti peak was somewhat more broadened than the Cr peak.

Figure 5 presents a summary of some electrochemical results for samples immersed in duaerated $1 \mathrm{wt} . \% \mathrm{NaCl}$ solution. The results presented are the pitting potential and a potential that characterizes the resistance to pit propagation. This latter indication is taken as the potential at a current offset of $1 \mathrm{~mA} / \mathrm{cm}^{2}$. Potentials are represented relative to the standard hydrogen electrode (SHE). Although the results are 
not presented graphically, it was observed that the open circuit corrosion potentials were generally unaffected by ion implantation for $\mathrm{N}$ and $\mathrm{Cr}$ treatments. Corrosion potentials were about $-0.75 \mathrm{~V}$ for these cases and for unimplanted material. For $\mathrm{Si}$ and $\mathrm{Ti}$ treatments, the corrosion potential was increased to approximately $-0.4 \mathrm{~V}$, and for both Si fluencies the corrosion potential apparently exceeded the pitting potential for $1100 \mathrm{Al}$. Elevation of the surface to a high floating potential may be the reason that Si-implanted samples were rather susceptible to pitting in the salt spray test. For Ti-implanted Al the corrosion potential remained slightly less than the pitting potential.

The most striking positive indication of Fig. 5 is the marked improvement in pitting potential for $1100 \mathrm{Al}$ for certain nitrogen implantations. These results for $1100 \mathrm{Al}$ are in contrast to those for $2014 \mathrm{Al}$, for which nitrogen produced essentially no effect on the electrochemical indicators. Apparently for nitrogen, there is an optimal dose, which is less than the maximum. This result seems broadly in agreement with that of Venkatraman et al.[4]

Salt fog testing of $\mathrm{N}$-implanted $1100 \mathrm{Al}$ produced an oxide which differed considerably in appearance from that which was formed on unimplanted $2014 \mathrm{Al}$ or on $\mathrm{N}$ implanted $2014 \mathrm{Al}$. The coating on 1100 was smooth (profilometry) and of a rather uniform tan color. The appearance was independent of nitrogen dose for 10,20, and 30 at. \% treatments. The coating was essentially $\mathrm{Al}_{2} \mathrm{O}_{3}$ of some microns in thickness, as was determined by RBS analysis.

Oxides on many samples subjected to salt fog testing were surveyed by RBS, and the histograms were compared with that derived from a high-purity $\mathrm{Al}_{2} \mathrm{O}_{3}$ insulator. Although the spectra have not been analyzed in quantitative detail, it: was judged that the composition of the oxides is generally close to the stoichiometry of $\mathrm{Al}_{2} \mathrm{O}_{3}$. No Na or $\mathrm{Cl}$ was detected in corrosion products. Occasionally unexpected elements were detected. One batch of samples had appreciable carbon incorporated in the oxide. 
In general $1100 \mathrm{Al}$ performed better than $2014 \mathrm{Al}$ for both salt fog testing and for electrochemical testing. This statement applies for unimplanted samples and for any given implantation treatment. The electrochemical indicators for the as-polished samples (Fig. 5) are exceptions. Likewise, mechanically polished 2014 Al performed better than "A" polished for given surface treatments and tests. These results are consistent with the idea that $\mathrm{Cu}$ concentration at the surface may be a key factor in susceptibility of $2014 \mathrm{Al}$ to pitting corrosion.

Preliminary results on dose dependency for $\mathrm{Cr}$ implantations have indicated that the dose of $3 \times 10^{17} / \mathrm{cm}^{2}$ at $150 \mathrm{keV}$ may be about optimal for that energy. The improvement for $1.5 \times 10^{17} / \mathrm{cm}^{2}$ is not as great. There is not much, if any, more improvement for $4.5 \times 10^{17} / \mathrm{cm}^{2}$ than for $3.0 \times 10^{17} / \mathrm{cm}^{2}$. From RBS the measured retained doses were $1.4,2.7$, and $3.7 \times 1017 / \mathrm{cm}^{2}$ for the respective nominal doses (determined from current integration) of $1.5,3.0$, and $4.5 \times 10^{17} / \mathrm{cm}^{2}$. At the lowest dose the difference of $7 \%$ is mostly due to error in either dosimetry, RBS determination or both. The progressively larger fractional differences at higher doses are due to saturation effects resulting from sputtering.

\section{Conclusions and discussion}

The most important among the results cited above is that $\mathrm{Cr}$-ion implantation produced a large improvement in the pitting corrosion resistance of $2014 \mathrm{Al}$. The reason for this improvement is not known. It is well known that $\mathrm{Cr}$ provides pitting resistance in stainless steels and in nickel based alloys such as Hastelloys. Passive films based on chromium oxide are known to be more resistant to reduction by $\mathrm{Cl}$ than films based on aluminum oxide. In this connection, it may be significant that $\mathrm{Cr}_{2} \mathrm{O}_{3}$ and $\mathrm{Al}_{2} \mathrm{O}_{3}$ are completely miscible as an oxide alloy. Since much of the the susceptibility of $2014 \mathrm{Al}$ 
to pitting appears related to the presence of the $\mathrm{Cu}$, it is also possible to speculate that some interaction with the $\mathrm{Cu}$ is a reason for the favorable result. For example $\mathrm{Cr}$ metal, like $\mathrm{Cu}$, has little solubility in $\mathrm{Al}$. Perhaps some of the implanted $\mathrm{Cr}$ joins preexisting $\mathrm{Cu}$ rich precipitates to produce a more highly enhanced $\mathrm{Cr}$ concentration in the precipitates than in the Al matrix. The $\mathrm{Cr}$ does produce more favorable pitting and pit propagation potentials than any other implanted constituent in $2014 \mathrm{Al}$.

The chromium treatment has possible practical applications. One issue that pertains to some applications is the resistance of the surface treatment to corrosion and simultaneous fretting action. For such a situation the choice of best surface treatment may depend on the nature of the fretting action. Brittle coatings with sharp interfaces at the substrate (e.g. anodic oxide, CVD coatings) might be vulnerable to fracture, breakup and spalling due to various types of impact. As an integral part of a ductile substrate, an ion implanted surface might be resistant tc a certain amount of peening action, but certainly could not resist severe gouging by sharp asperities.

Quality control throughout all phases of execution, including preparation of surfaces for implantation, could well be important for successful application. For example in the present study, the possibility of various amounts of oxygen being present on mechanically polished samples was not anticipated. This oxygen did not affect the main conclusions, but may have introduced uncertainty in quantitative results such as amount of oxygen added in certain tests, or in electrochemical potentials for control samples.

For a result such as that of the $\mathrm{Cr}$-implanted sample, shown in Fig. 2, the question might arise as to whether the apparent success of ion implantation on that particular sample (part of surface treated and part untreated) is cue to making the implanted area more noble, so that the untreated area becomes sacrificial. This issue will not be discussed, but there are reasons why we do not believe that is the case. 
Nitrogen is an inexpensive treatment, and it would appear from the electrochemical studies that $\mathrm{N}$-implantation is promising, at least for some aluminum alloys in some applications. In the severe tests of the present study, however, nitrogen produced no benefit for $2014 \mathrm{Al}$ (consistent with the electrochemical results) and perhaps a marginal benefit for $1100 \mathrm{Al}$ for 10,20 , and 30 at. $\% \mathrm{~N}$. The $3 \times 10^{17} / \mathrm{cm}^{2}$ treatment at $20 \mathrm{keV}$ (Fig. 5) has not yet been tried with the salt fog.

It was judged that the salt spray results could be partially rationalized in terms of the electrochemical results.

\section{References}

1. A. J. Armini and S. N. Booker, Mater. Sci. \& Eng. A115 (1989) 67.

2. ASTM Designation B117-73 (Reapproved 1979), Standard Method of Salt Spray (Fog) Testing. 1984 Annual Book of ASTM Standards, Vol 03 02. Metal Corrosion, Erosion and Wear, p 32, ASTM, 1984.

3. Wei-Kan Chu, James W. Mayer and Marc-A. Nicolet, BACKSCATTERING SPECTROMETRY, Academic Press, New York, 1978.

4. S. Venkatraman, M. R. Nair, D. C. Kothari, and K. B. Lal, Nucl. Instr. and Meth. $B 19 / 20$ (1987) 241.

\section{DISCLAIN:ER}

This report was prepared as an account of work sponsored by an agency of the United States Government. Neither the United States Government nor any agency thereof, nor any of their employees, makes any warranty, express or implied, or assumes any legal liability or responsibility for the accuracy, completeness, or usefulness of any information, apparatus, product, or process disclosed, or represents that its use would not infringe privately owned rights. Reference herein to any specific commercial product, process, or service by trade name, trademark, manufacturer, or otherwise does not necessarily constitute or imply its endorsement, recom. mendation, or favoring by the United States Government or any agency thereof. The views and opinions of authors expressed herein do not necessarily state or reflect those of the United States Government or any agency thereof. 


\section{FIGURE CAPTIONS}

Figure 1. Rutherford backscattering histograms for Al alloy samples hat have been prepared for ion implantation and corrosion testing. $2.0 \mathrm{Mev}$ He ions. $160^{\circ}$ scattering angle.

Figure 2. Photograph showing coupons of $2014 \mathrm{Al}$, new, after various ion implantation treatments and salt fog testing, and as-tested with no ion implantation. Starting surfaces were all mechanically polished. Ion implanted areas were $2 \mathrm{~cm}$ in diameter, and the ion implanted samples were halved after salt testing. $168 \mathrm{~h}$ salt fog test. ORNL Photo 678490.

Figure 3. Profilometer trace over the transition from implanted area to unimplanted area for the Cr-implanted sample of Fig. 2. (ORNL-DWG 90-M-14917)

Figure 4. Rutherford backscattering histograms for the Cr-implanted sample of Fig. 1 (implanted and tested) and for a typical as-implanted sample for Cr. $3 \times 10^{17} / \mathrm{cm}^{2} \mathrm{Cr}$ at $150 \mathrm{KeV}$.

Figure 5. Electrochemical potentials characterizing pit iniation and pit propagation for $1100 \mathrm{Al}$ and for $2014 \mathrm{Al}$ for as-prepared samples and for samples with various ion implantation treatments. The as-polished 2014 sample had the mechanical polish. (ORNLDWG 90-M-14614) 


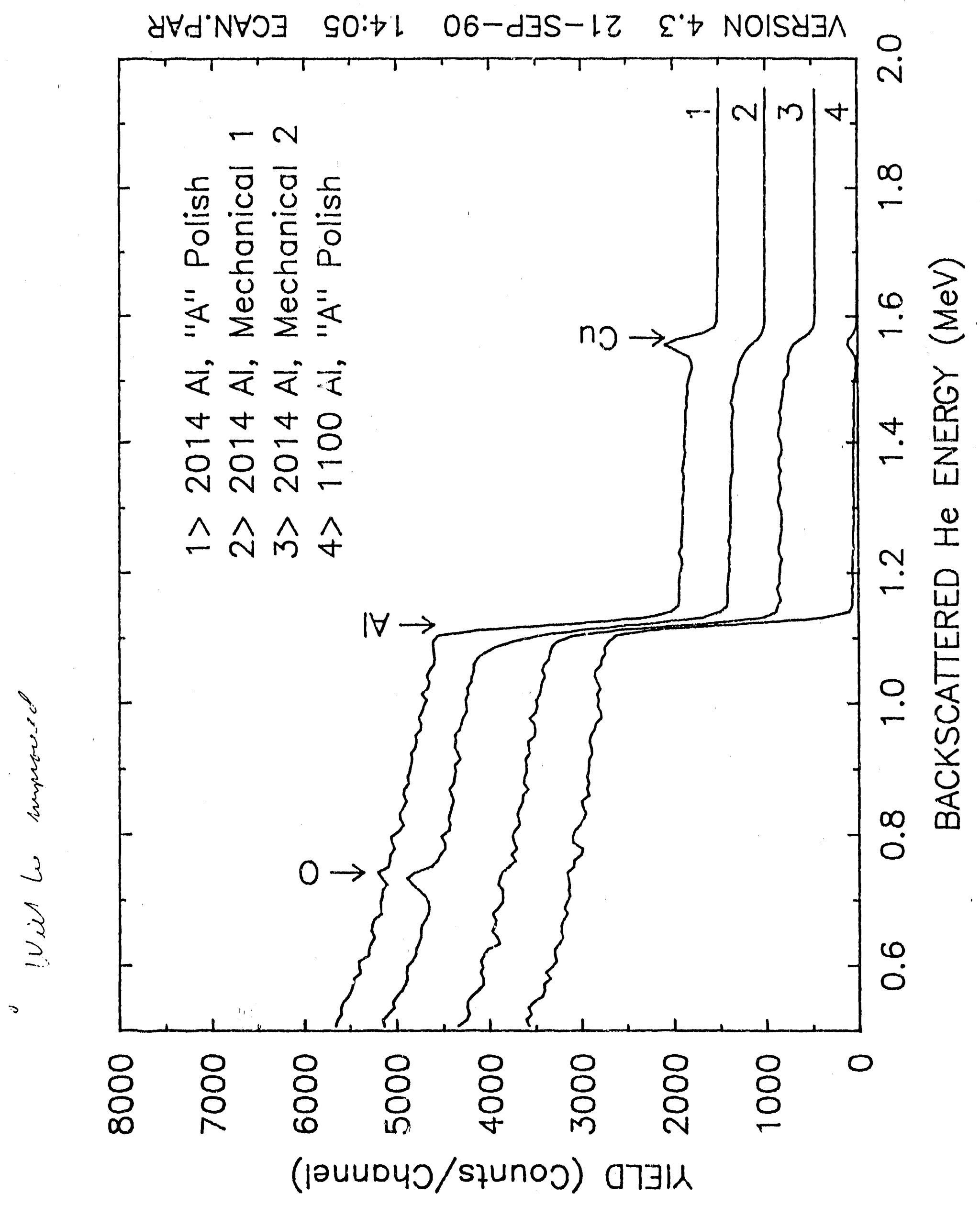


TNEW SAMPLE - UNIMPLANTED, UNTESTED

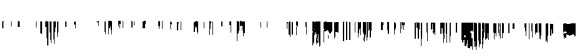



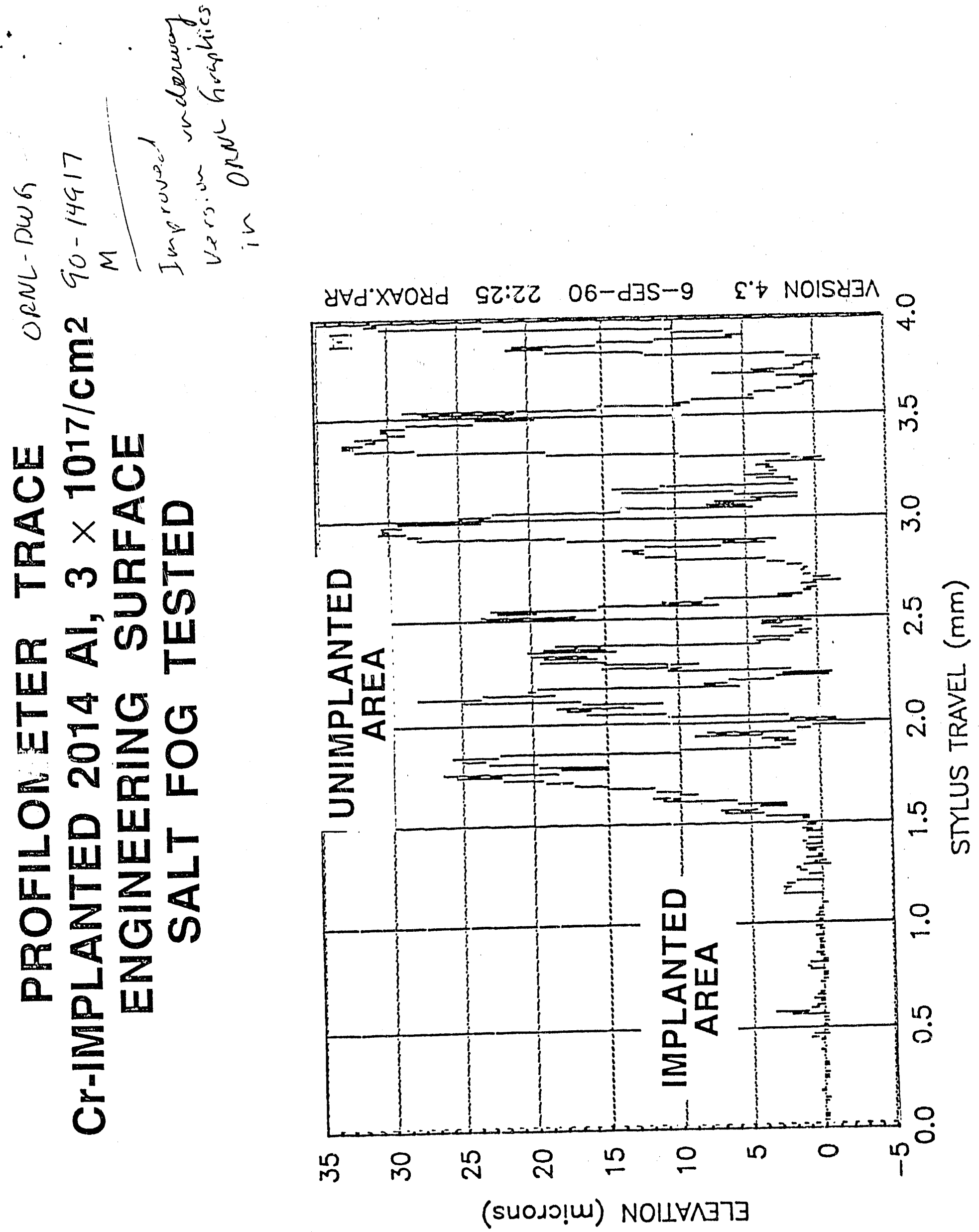


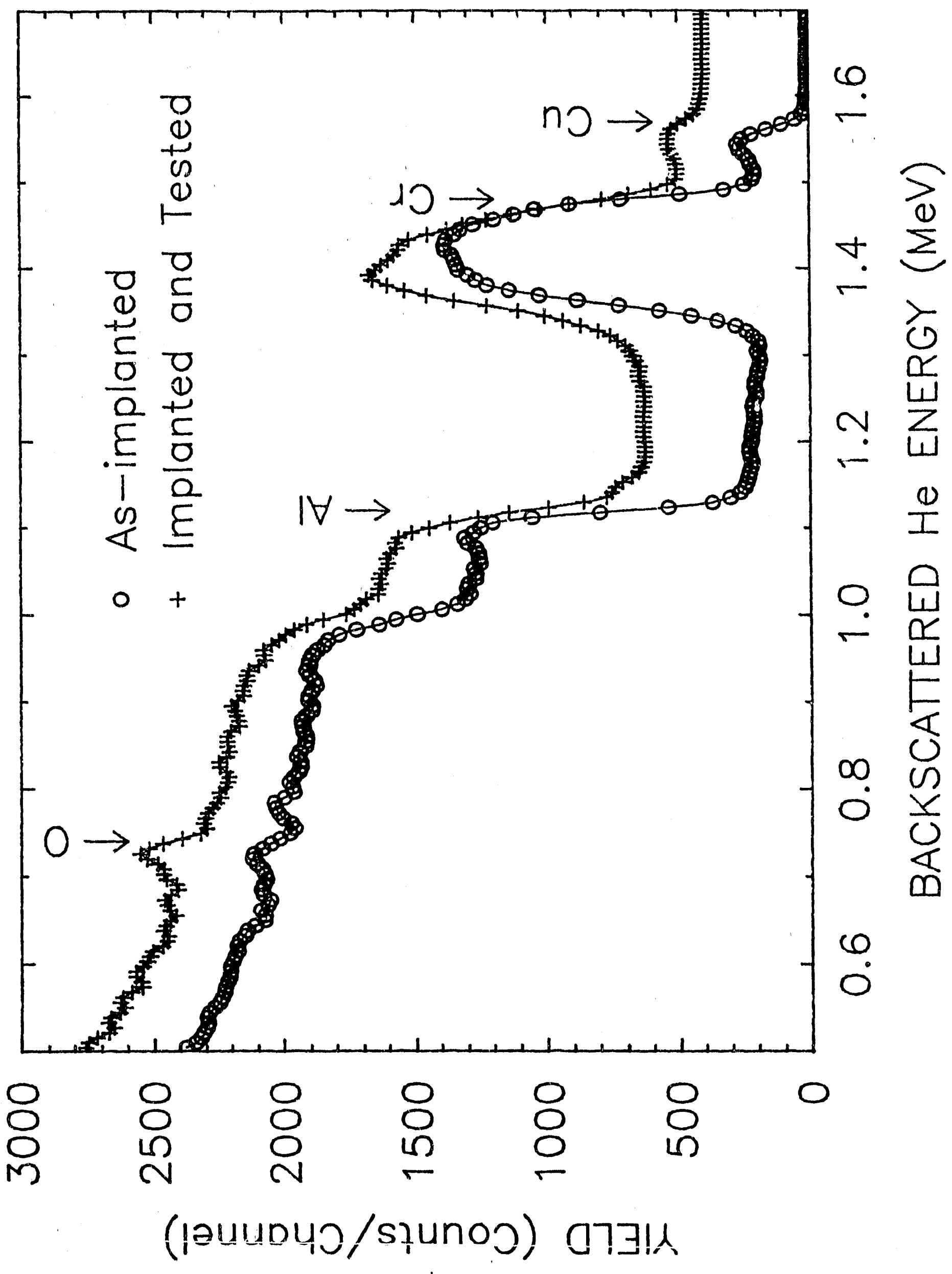




\section{Electrochemical Potentials Characterizing Pit Initiation and Pit Propagation for $1100 \mathrm{Al}$ and for $2014 \mathrm{Al}$ with Various Surface Treatments}

As-POLISHED $1100 \mathrm{AI}$

N-IMPLANTED $1100,3 \times 10^{17} / \mathrm{cm}^{2}, 20 \mathrm{keV}$

N-IMPLANTED $1100,6 \times 10^{17} / \mathrm{cm}^{2}, 20 \mathrm{keV}$

N-IMPLANTED 1100,10 at. \% avg. conc.

N-IMPLANTED 1100,20 at. \% avg. conc.

N-IMPLANTED 2014, 20 at. \% avg. conc.

N-IMPLANTED 1100,30 at. \% avg. conc.

TI-IMPLANTED $1100,3 \times 10^{17} / \mathrm{cm}^{2}, 130 \mathrm{keV}$

Si-IMPLANTED $1100,2 \times 10^{17} / \mathrm{cm}^{2}, 60 \mathrm{keV}$

SI-IMPLANTED $1100,4 \times 10^{17} / \mathrm{cm}^{2}, 60 \mathrm{keV}$

Cr-IMPLANTED 2014, $3 \times 10^{17} / \mathrm{cm}^{2}, 150 \mathrm{keV}$

Cr-IMPLANTED $1100,5 \times 10^{16} / \mathrm{cm}^{2}, 35 \mathrm{keV}$

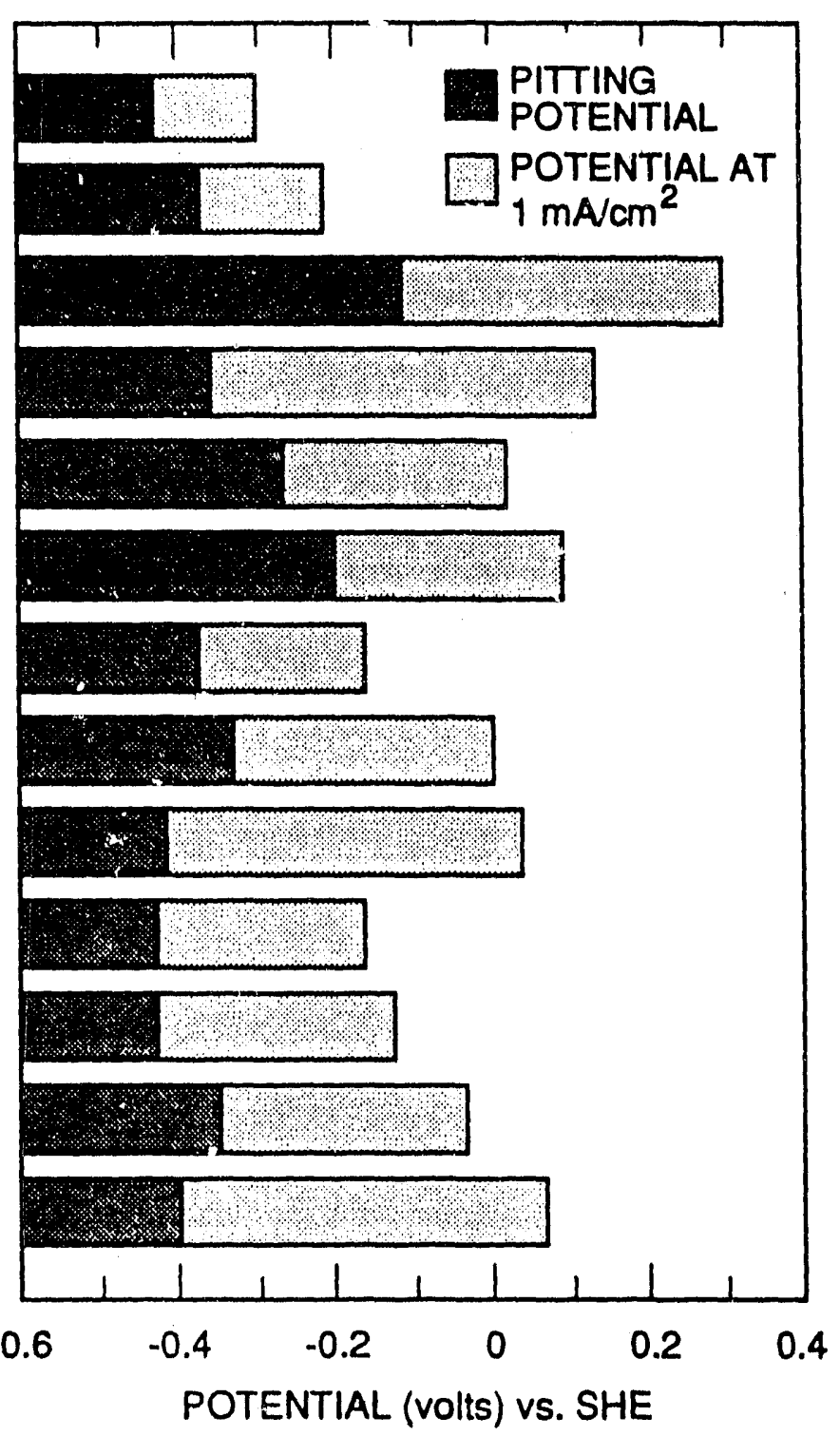



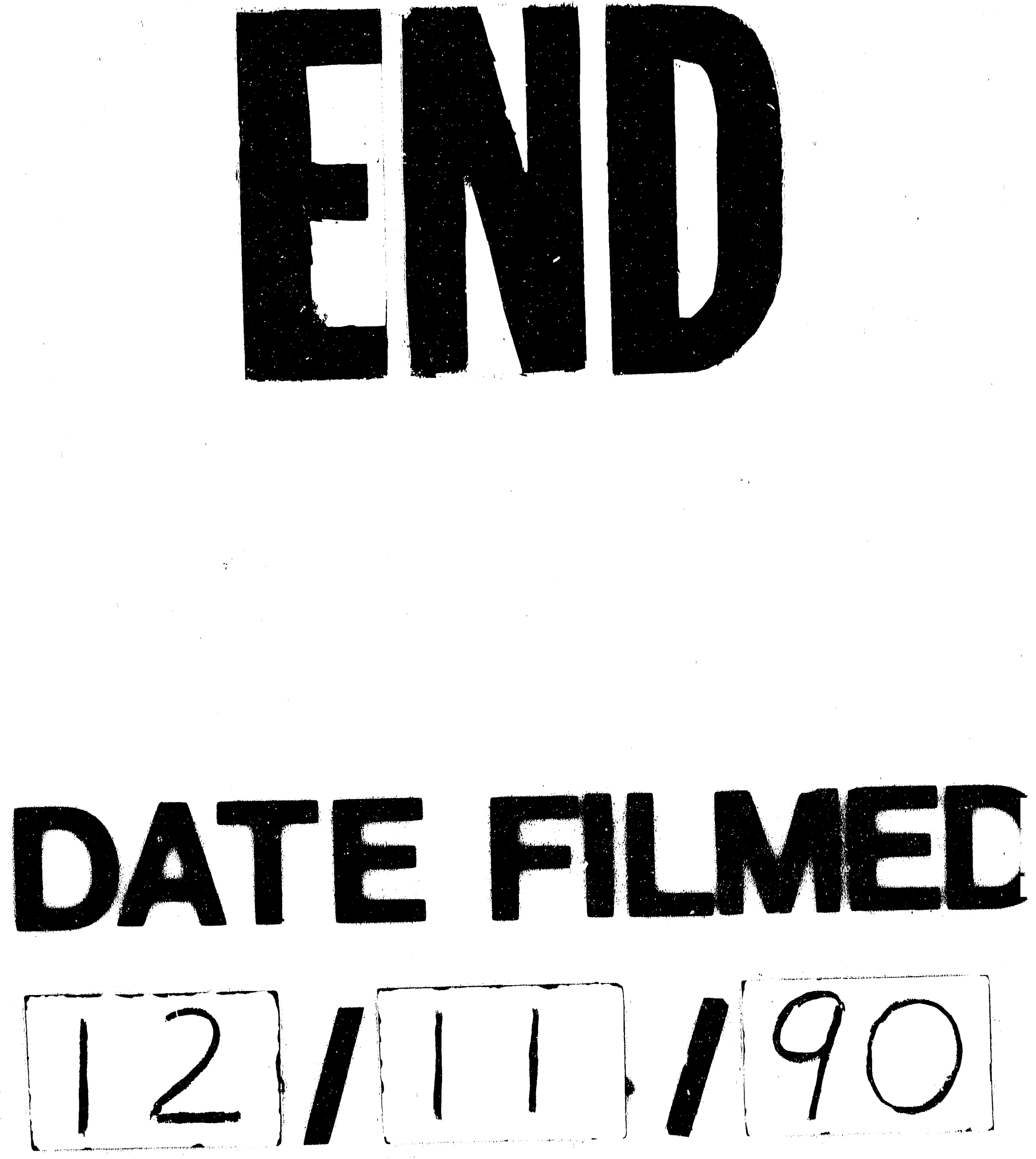
